\title{
Notas sobre a formação de universitários e povos de terreiro: experiências com educação popular em saúde em Juazeiro do Norte, Ceará
}

Tadeu Lucas de Lavor Filho1, Carlos André Silva do Vale²

\begin{abstract}
Resumo
O presente artigo traz uma discussão reflexiva de vivências com ações afirmativas a partir do projeto de extensão "Encontros e encantos: educação popular e saúde com povos de terreiros de matriz africana em Juazeiro do Norte-CE". O trabalho tem como objetivo discutir a experiência de um projeto de extensão universitária na formação de profissionais e povos de terreiro com base na educação popular de Paulo Freire. Foi articulado o debate de formação em saúde com vista às demandas particulares dos povos de terreiros de Juazeiro do Norte, tomando como cunho metodológico as cartilhas de saúde do Sistema Único de Saúde (SUS) que fazem referência a essa discussão temática. Problematizamos a necessidade de reestruturação político-pedagógica da formação no campo das ciências humanas e saúde, tendo em vista que ainda existe o empobrecimento de debates que aplaquem as demandas reais dos terreiros de candomblé e uma produção tendenciosa do conhecimento acerca do saber localizado, marcada pelo branqueamento e a colonização do saber. Portanto, os atores envolvidos nos processos educativos são transformados pela interação dos seus elementos comuns e particulares. Por meio da extensão foi possível pensar uma prática profissional implicada com discussões éticas, humanas e socioculturais que atravessam a subjetividade, apontando a emancipação e descolonização do saber universitário.
\end{abstract}

\section{Palavras-chave}

Educação Popular. Extensão. Terreiro. Emancipação.

1. Mestrando em Psicologia na Universidade Federal do Ceará, Brasil. E-mail: lucasamoha@gmail.com.

2. Psicólogo Residente em Saúde Coletiva no Instituto de Medicina Integral Fernando Figueira, Recife, Brasil; especializando em Saúde Mental pela Universidade Regional do Cariri, Ceará, Brasil. E-mail: carlosdovale7@ gmail.com. 


\title{
Notes on the training of university and povos de terreiro: experiences with popular education health in Juazeiro do Norte, State of Ceará, Brazil
}

Tadeu Lucas de Lavor Filho*, Carlos André Silva do Vale**

\begin{abstract}
This article brings a reflective discussion of experiences with affirmative actions through the extensions project “Encontros e encantos: educação popular e saúde com povos de terreiros de matriz africana em Juazeiro do Norte-CE". The objective of this work is to discuss the experience of a university extension project in the training of professionals and "povos de terreiro" based on the popular education of Paulo Freire. The debate on health education was articulated with a view to the private demands of the "povos de terreiro" de Juazeiro do Norte, taking as a methodological guideline the health booklets of the Unified Health System that refer to this thematic discussion. We problematize the need for a politicalpedagogical restructuring of training in the field of human sciences and health, considering that there is still the impoverishment of debates that apply to the real demands of the Candomblé fields and a tendentious production of knowledgeabout localized knowledge, marked by bleaching and the colonization of knowledge. Therefore, the actors involved in the educational processes are transformed by the interaction of their common and particular elements. Through extension it was possible to think about a professional practice implied in ethical, human and sociocultural discussions that cross subjectivity, pointing to an emancipation and decolonization of university knowledge.
\end{abstract}

\section{Keywords}

Popular Education. Extension. Terreiro. Emancipation.

\footnotetext{
* Master degree student in Psychology at the Federal University of Ceará, State of Ceará, Brazil. E-mail: lucasamoha@gmail.com.

** Resident Psychologist in Collective Health at Instituto de Medicina Integral Fernando Figueira, Recife, State of Pernambuco, Brazil; specializing in Mental Health from the Regional University of Cariri, State of Ceará, Brazil. E-mail: carlosdovale7@gmail.com.
} 


\section{Introdução}

O presente artigo tem como objetivo discutir a experiência de um projeto de extensão intitulado "Encontros e encantos: educação popular em saúde com povos de terreiros de matriz africana em Juazeiro do Norte-CE", a partir de encontros realizados nesse município. Tendo como base a educação popular de Paulo Freire, discutiremos a formação de universitários consonantes com a formação de povos de terreiro em educação popular. Partese da aposta que a formação universitária é permeada de agenciamentos implicados no ensino, na pesquisa e na extensão. Por isso, acreditamos que os encontros potentes de diálogo, facilitação, produção coletiva do conhecimento e experiências singulares são efetivas para a formação do pensamento crítico.

$\mathrm{O}$ projeto de extensão realizado tem sua premissa na Política Nacional de Educação Popular em Saúde (PNEPS-SUS), em que se constitui como política e funcionamento da saúde pública com elementos de cunho participativo, integrativo e de equidade dos modos de fazer saúde. É nessa práxis que encontramos referenciais de Paulo Freire com educação popular, a qual se insere na perspectiva de que o saber é agente transformador da realidade social e, consequentemente, potencializador dos processos de conscientização e saúde de população (BRASIL, 2013). Com isso, a PNEPS possui referenciais teórico-metodológicos cunhados na defesa da democracia, articulação de saberes populares e científicos, solidariedade, fortalecimento de vínculos, cidadania, valorização do saber popular e empoderamento da comunidade nos contextos de saúde (BOTANNI et al., 2014).

O caráter de uma extensão universitária é atravessado pela conexão do trabalho de ensino e pesquisa pertinente à realidade social emergente da relação universidadecomunidade e vice-versa. Desse modo, na esfera do ensino, a extensão proporciona a construção de conhecimento compartilhado com os sujeitos envolvidos no processo e, no âmbito da pesquisa, sua aplicação possibilitar criar e repensar metodologias participativas efetivas nos mais diversos campos. Por conseguinte, a extensão além de tornar sólida a formação universitária implicada com questões e demandas sociais, tende a produzir redes de saberes com a coparticipação do saber popular e do saber científico no fortalecimento de um conhecimento implicado com o cotidiano. Para isso, na concepção de extensão encontramos a base freiriana de trabalho de mudança da realidade de cunho popular no combate às opressõeseasdesigualdades (MELONETO, 2014).

A linha freiriana se alimenta do espírito da esperança que, através das possibilidades de mudança, criação e inovação das práticas pedagógicas, promove o respeito às singularidades dos agentes no processo de aprendizagem. Isso é percebido no olhar dado para a relação horizontalizada entre educando e educador. Nesse processo existe o encontro entre os elementos singulares que compõem suas particularidades. A forma compartilhada e dialógica são marcas que caracterizam o saber libertador e transformacional proposto por Freire (2000). Nesse ínterim, ao contextualizarmos tal visão com os períodos históricos da educação brasileira, no período compreendido entre os séculos XVI e XX, percebe-se que os lugares ocupados entre o conteúdo aprendido, o educando e os educadores nem sempre estiveram em sintonia com as demandas pedagógicas, sociais, políticas e econômicas para a construção de um país democrático e equânime. Logo, pode-se dizer que os sistemas educativos brasileiros iniciaram sua formação sendo fragmentados, dissonantes das problemáticas emergentes no país e solidários 
a um projeto sócio-político que objetivava o progresso e o desenvolvimento urbanoindustrial-empresarial, a concentração de renda e, como consequência, a estratificação social (GHIRALDELLI JUNIOR, 2013).

Desse modo, a educação e a sociedade são duas dimensões coletivas que interagem com a formação humana, haja vista que esses componentes coletivos se constroem nos sistemas sociocomunitários, socioambientais, psicossociais e interpessoais a partir de elementos dinâmicos que dialeticamente possibilitam a transformação de um contexto individual e grupal (GHIRALDELLI JUNIOR, 2013).

Sobre isso, Gallo (2006) exemplifica essa relação entre educação e sociedade, mediante as recortes tempo-espaciais na construção do modelo pedagógico-social das instituições educativas no Brasil. O autor apresenta que, até meados da metade do século XX, as práticas pedagógicas tinham o intuito de formar mãode-obra para atender ao desenvolvimento fabril e urbano das metrópoles brasileiras.

Para Gallo (2006), essa situação veio sendo modificado a partir da década de 1950, quando o país passou por fortes alterações na sua estrutura geopolítica, nos sistemas de gestão social-democrática e participação da população. Em um contexto paradoxal de instabilidade política e societal, censura e extrema violência coexistiam no mesmo período de organização dos movimentos sociais, que agiam em prol de uma prática educativa voltada para a promoção da cidadania e da cultura para a paz.

Assim, como território de múltiplas dimensões humanas, mercadológicas, tecnológicas e culturais, os sistemas educativos podem propiciar, além da compreensão dos fenômenos ontológicos e gnosiológicos da humanidade, o engajamento político e social das pessoas, em busca de transformar suas realidades (GALLO, 2006). Sob o mesmo ponto de vista, a educação como ferramenta sociopolítica pode agir de forma paradigmática, possibilitando modificações da realidade para melhoria na qualidade de vida das pessoas ou manter o status quo de opressão e desigualdades sociais.

São nessas incertezas dos processos educativos que este trabalho foi construído. Os construtos teóricos, conceituais e práticos da linha freiriana com educação popular fizeram com que as problemáticas vividas pelos extensionistas do Programa de Ações Afirmativas do Centro Universitário Doutor Leão Sampaio (Unileão) fossem combustíveis para se buscar dialogar e compartilhar as vivências com essa prática teórica e reflexiva da linha freiriana através do projeto de extensão supramencionado. As inquietações dos monitoresextensionistas estão ao longo do texto em forma de relatos descritivos das suas experiências. Buscou-se estreitar os vínculos da universidade com os terreiros de Candomblé do munícipio de Juazeiro do Norte-CE mediante a concretização das ações políticas e pedagógicas desse pilar da educação. Os terreiros participantes foram: o Terreiro de Àlakétou - IléÀlakétouljobáÀséÒlógùnEdé e Oiyá (Atin Casa de Òsumaré), Terreiro de Djèdjè- Nagò - Ilé Omindandereci y Mutalegí, o Terreiro Âlakétou - Ilé Àsé Òsún Tunjí (Atin Casa de Òsumaré) e o Egbé Ifá Agbonniregun Odú Okaròn Até, todos localizados no Cariri cearense, durante os anos de 2016 a 2018.

\section{0 percurso da construção do projeto}

A construção de um plano pedagógico e político para as ações afirmativas dentro da Unileão surgiram a partir de alianças e rupturas pessoais e institucionais, em uma perspectiva interinstitucional do ensino público e privado no Cariri. As universidades públicas da região, a Prefeitura de Juazeiro do Norte e a Ordem dos Advogados do Brasil (OAB), sede Juazeiro do Norte, filiaram-se às propostas de construir perspectivas teóricas, conceituais e práticas que abarcassem as discussões sobre 
violência no segmento étnico-racial, de gênero e na segurança pública, encabeçadas pelo Laboratório Interdisciplinar de Estudos da Violência (LIEV) na Unileão desde 2014.

O LIEV encontra-se sob a responsabilidade do curso de bacharelado em Direito do Centro Universitário, mas conta com o apoio transversal dos cursos de Psicologia, Serviço Social, Filosofia e Pedagogia, com o objetivo de possibilitar discussões e ações de promoção à democracia das atuais conjecturas acerca da visibilidade e diversidade de gêneros, a superação de paradigmas de opressão e dominação ideológica, mercadológica e científica e os impasses da intolerância religiosa presente na região metropolitana do Cariri (GOMES FILHO; MELO; QUEIROZ, 2017).

O gatilho para concretizar as ações de estudos e pesquisa do LIEV ocorreu com a solicitação da ONG Instituto Cultural ljoba de Educação Afro-brasileira (ICIEAB), localizada no bairro das Pedrinhas, em Juazeiro do Norte, em 2015, ao grupo de pesquisadores e professores vinculados a esse dispositivo. Essa solicitação continha o desejo do desenvolvimento de ações de promoção à saúde dentro dos terreiros de Candomblé do município. Dessa forma, os coordenadores do laboratório encontraramse no binômio necessidade e demanda, buscando estratégias para consolidar tal pedido.

Um caminho possível foi trazer essa questão para dentro da universidade, mediante as propostas de iniciar uma extensão acadêmica voltada para esse público. Essa ferramenta potente e pedagógica de buscar aproximação das instituições de ensino superior com a realidade concreta ocorre na relação com a materialidade dos sujeitos no seu cotidiano, ou seja, no seu modo de produzir suas particularidades na sua comunidade e nos espaços que compõem (SERRANO, 2008). Assim, em 2016, foi montado o projeto piloto Educação popular e saúde com povos de terreiro em Juazeiro do Norte-CE, com a intenção de tornar as ações afirmativas uma realidade concreta dentro e fora dos muros da universidade privada. Sustentado pela proposta jurídico-pedagógica das Diretrizes Nacionais para Educação das Relações ÉtnicoRaciais e para o Ensino de História e Cultura Afro-Brasileira e Indígena (Lei no 11.645 de 10 de março de 2008; Resolução CNE/CP no 01 de 17 de junho de 2004) e a militância de discentes e docentes da instituição. A ideia era a promoção do protagonismo da população negra na cidade de Juazeiro do Norte com o enfoque nos terreiros de religiões de matrizes africanas da região, que se dispuseram a (co)participar na montagem de estratégias de fortalecimento do empoderamento sociocomunitário, que envolvia a afirmação das identidades religiosas ligadas ao sagrado tribal e à garantia dos direitos fundamentais da população negra no Cariri (GOMES FILHO; MELO; QUEIROZ, 2017).

A justificativa para o projeto, além de cunho político e institucional, passou por um aparato de discussões científicas que envolviam as particularidades quanto à visibilidade negra dentro das políticas públicas de saúde e socioassistenciais. Isso é retratado no documento base para a discussão desse construto, a saber, a Cartilha Saúde Brasil 2013, que mostra como os determinantes sociais têm promovido omissão e negligência das ações estatais para efetivarem políticas de equidades e de superação das injustiças sociais, o que corrobora para um ciclo de violência, exclusão e marginalização das populações negras e de espaços periféricos no país (BRASIL, 2014).

Dessa maneira, munidos dos motivos para prosseguircomaexecuçãodoprojeto, ainstituição realizou um processo seletivo organizado pela Comissão de Pesquisa e Extensão (COPEX) da Unileão para os monitores-extensionistas, envolvendo os cursos de Direito, Psicologia e Serviço Social. Os pré-requisitos para adentrar nessa aposta envolveram o alinhamento teórico 
e conceitual com as perspectivas societárias e políticas da educação popular em saúde.

Esse arcabouço epistemológico dos extensionistas deveria ser alinhado ao escopo da pedagogia problematizadora, às discussões freirianas acerca da relação educação e liberdade, à educação como revolução, ao modo de superação dos sistemas de opressão e ao processo educativo dialógico, horizontalizado, emancipatório e ontológico (SILVA, 2009).

Um dos marcos que nortearam o planejamento do projeto e o seu desenrolar foi a Política Nacional de Educação Popular em Saúde (PNEPS-SUS) com a Portaria no 2.761, de 19 de novembro de 2013, que estabelece, dentro das ações políticas e institucionais, o que é necessário para se considerar uma prática de educação popular em saúde, como, por exemplo: fomentar ações de participação popular, possibilitar a construção de maneiras de gestão participativa, desenvolver mecanismos de controle social, promover a dialogicidade, incentivar o protagonismo social e instrumentalizar estratégias de cuidado em saúde (BRASIL, 2013).

Dessa maneira, buscamos interconectar as perspectivas da educação popular com as atribuições das ações afirmativas na área da saúde, que estão garantidas na Política Nacional de Saúde Integral da População Negra, fazendo cumprir seus objetivos de reduzir e combater formas discriminatórias na dimensão étnico-racial e promover saúde a partir da garantia dos direitos humanos e das especificidades dos determinantes socioculturais dessa população (BRASIL, 2009).

Vale considerar que as ações afirmativas são intervenções políticas, jurídicas, sociais e institucionais, com as quais se busca a equidade de acesso aos direitos fundamentais aos grupos populacionais segregados e excluídos das ações estatais. Salienta-se que essa iniciativa pode ser pública e/ou privada, tendo o propósito de diminuir os efeitos dos processos de apagamento social das populações violentadas por seus marcadores coletivos de raça, etnia e gênero (MOEHLECKE, 2002). Posto isso, os movimentos institucionais e pessoais para a realização do projeto objetivaram a busca de superar paradigmas discriminatórios e de desigualdades sociais envolvidos na construção sócio-histórica da identidade negra na região. Logo, buscamos fortalecer ações de cunho institucional desenvolvidas pelos terreiros, como a Afroquermece e as Caminhadas em Prol da Liberdade Religiosa, a partir do engajamento institucional e o apoio organizativo desses momentos políticos que marcam a luta regional pelo respeito à diversidade religiosa no Cariri.

Os métodos adotados envolveram aulas expositivas e dialogadas, oficinas de produção artística e rodas de conversas, organizadas de forma modular e mensal. Essas ferramentas tiveram como propostas a imersão na realidade da dinâmica relacional e institucional dos terreiros e a promoção do conhecimento compartilhado, aliado à compreensão teóricoprática de um trabalho coletivo e vivência da realidade social que se vive (MELO NETO, 2017).

Portanto, o cronograma não foi uma imposição, mas uma construção conjunta e compartilhada de caráter dinâmico e inacabado, sendo dividido seguindo algumas dessas propostas: História da educação brasileira: da diáspora africana e dos povos negros escravizados para o Brasil; Exclusão, inclusão e cultura do negro; Religiões afro-brasileiras na literatura e na televisão: desconstruindo estigmas sociais, construindo identidades; $\mathrm{O}$ uso de meios alternativos de solução de conflitos a partir da mediação por liderança religiosa na comunidade; Conflitos e adoecimento mental causado por violência de gênero/ sexo, raça e religiosidade; Adoecimento mental provocado por atos de intolerância religiosa, racismo e sexismo; Consciência, cultura e autoestima sob o foco dos estudos culturais; Liberdade religiosa e liberdade de crença; Comunicação 
não violenta e o Teatro do Oprimido; e O que o terreiro tem a dizer sobre gênero? Para a efetivação desses momentos, uma das ferramentas encontradas para estreitar os laços entre os extensionistas e a os candomblecistas foi buscar superar o modelo científico de colonização do saber popular, dando ênfase às propostas dos Círculos de Cultura. À vista disso, essa estratégia que compõe a educação popular tem como perspectiva um modelo compreensivo, prático e político, em que os sujeitos são livres para expor sua forma de compreensão da realidade, sendo eles os próprios autores sociais que narram e se implicam quanto à construção da sua história (FREIRE, 2014b).

O projeto encontrou com os Círculos de Cultura um fazer potencializador, e clarificou que os métodos tradicionais de encontros expositivos e dialogados estavam sendo insuficientes para abarcar as demandas pulsantes no grupo. Em vários momentos dos encontros, percebeu-se um forte movimento dos sujeitos darem sentidos ao material exposto com a sua realidade de terreiro, buscando de certa forma uma aplicabilidade. Foi nesta dificuldade que as ações de extensão começaram a mobilizar a construção dos Círculos de Cultura articulados com demandas sociais compartilhadas pelos pais e filhos de santo, por exemplo: questões operacionais e de responsabilidade no terreiro, dinâmicas psicossociais dos filhos e filhas de santo e sua relação com o trabalho.

Entendendo esse momento como essencial para o processo da extensão, formaram-se os Círculos de Cultura em que os babalorixas, lalorixas, filhos e filhas de santo, falassem sobre o cotidiano e a forma como construíam seu convívio social. À medida que se esses diálogos foram construídos, fez-se com que algumas palavras-chave fossem por eles destacadas, a saber: "responsabilidade com ancestralidade", "cuidado com o Bará", "a comida do santo", dentre outras. Com isso, esse movimento fez com que o projeto se rearticulasse para não levar material pronto, mas recursos para construir um diálogo compartilhado. Assim, os objetivos dos Círculos de Cultura apontam para uma relação estreita eaprofundada entre uso da linguagem e as práticas culturais, capazes de promover a libertação ideológica dos sistemas que mobilizam as dominações educacionais e mercadológicas, na medida em que facilitam, além da alfabetização e a leitura, a interpretação e a reedição da realidade por parte das pessoas, com o objetivo de transformar a si e seu contexto. De forma evidenciada, Freire (2014b, p. 8) diz que os Círculos de Cultura estão onde "a visão educacional não pode deixar de ser ao mesmo tempo uma crítica da opressão real em que vivem os homens e uma expressão de sua luta por libertar-se".

O projeto aconteceu de 2016 a 2018, sendo dividido em dois momentos no intervalo anual. No primeiro ano, contou com a colaboração do Instituto Cultural ljoba de Educação Afrobrasileira (ICIEAB) (Associação Cultural Alaketou ljoba Ase Logun edé-oya de Educação Afrobrasileira) e a Coordenadoria do GT Estadual de Mulheres de Axé- Renafro Ceará, onde, depois, os professores envolvidos na ideia inicial foram realizando convites e agregando parceiros, como o Instituto com Dendê, Renafro estadual, Renafro núcleo Cariri, Núcleo de Pesquisa em Cultura Popular Behetçoho (Curso de Letras), Núcleo de Estudo em Educação Brasileira e Afro-brasileira (Curso de Pedagogia), ambos na Universidade Regional do Cariri (URCA) e a própria Secretaria de Saúde e de Educação do município de Juazeiro do Norte.

\section{0 que fica movimenta e transforma a realidade}

Apesar do término do projeto, algumas considerações tornam esses momentos memoráveis e constitutivos na nossa formação, pois a partir dos debates e das reflexões dos 
encontros que é que se começou a problematizar a construção do modelo pedagógico usado nas salas de aula da instituição e o aparato teórico e conceitual utilizado na prática docente.

Do ponto de vista dos Parâmetros Curriculares Nacionais (PCN), as Leis $\mathrm{n}$ $10.639 / 2003$ e no 11.645/2008 estabelecem que os espaços educacionais devam fomentar ações de ensino e pesquisa educacionais para buscar desmistificar a subalternidade do povo africano e afro-brasileiro, implementar iniciativas de promoção às discussões sobre as multiculturas existentes no país e estabelecer que o ensino das relações étnico-raciais fazem parte de uma luta ética, política e social, que visa estabelecer a afirmação da cidadania e a garantia dos direitos humanos à população negra do país (NASCIMENTO, 2008). Retomando a experiência, percebemos o empobrecimento das discussões psicológicas quanto à cultura africana, dentro da sua composição de ritos, organização social, o papel político do negro e a própria tendência de "psicopatologizar" o fenômeno religioso da incorporação.

Em busca de ampliar as discussões e desmistificações quanto ao papel do psicólogo dentro da luta pela igualdade racial e o combate ao racismo, o Conselho Federal de Psicologia (CFP) coloca na Resolução no 18/2002 quais devem ser os posicionamentos de psicólogo em prol da garantia dos direitos humanos para todos. Mais recentemente, em 2017, o CFP divulgou o documento como a cartilha "Relações raciais: referências técnicas para a prática da(o) psicóloga(o)" para subsidiar as ações técnicas, teóricas e reflexivas desses profissionais no âmbito das políticas públicas (CFP, 2017).

Diante disso, percebemos que existem esforços da categoria para trazer as discussões sobre raça e etnia para além do âmbito clínico e individual. Todavia, a indagação que precisa ocorrer é por que esses tais assuntos são reduzidos na formação desses profissionais e qual a representatividade da cultura africana nos cursos de Psicologia no país? Acerca dessas inquietações, Sobrinho (2009) destaca que as roupagens das universidades guardam resquícios do eurocentrismo, assim o seu conteúdo tem cor, localização e objetivo. Sua cor branca vinculase à filosofia europeia burguesa dos séculos XIX e XX, visando afirmar um saber hegemônico diante das demais linhas de pensamento. Nesse sentido, percebemos a carência de debates da Psicologia que dialogassem com pensadores africanos ou afro-brasileiros. Os próprios educadores são peças mantenedoras do embranquecimento pedagógico. Eles não possuem aparato epistemológico para tais discussões, o que sinaliza que a omissão desses conhecimentos é estrutural e estruturante do modus operandi da educação brasileira universitária. Assim, vimos que esse processo de se pensar o multiculturalismo e o interculturalismo dentro dos cursos de Psicologia e Serviço Social estavam sendo explorados apenas pelo viés tendencioso e unicultural.

Essa reflexão política e social dentro do processo de construção pedagógica dos extensionistas faz lembrar as propostas de Delors (1996), na qual o caminho para a educação do século XXI deve ser construído e trilhado mediante a indissociabilidade do aparato humano, ético e técnico. O autor destaca quatro pilares para pensar a educação frente aos multissistemas de alienação populacional diante de fatores políticos e econômicos, que conduzem as sociedades para uma dominação ideológica e territorial: 1) aprendendo a conhecer; 2) aprendendo a fazer; 3) aprendendo a conviver; 4) aprendendo a ser (DELORS, 1996).

$\mathrm{O}$ primeiro pilar, aprendendo a conhecer, foi construído a cada encontro, à medida que houve o compartilhamento com os monitores da historicidade da tradição africana com os seus ritos, os seus dogmas, a sua organização institucional, os papéis dos seus membros, assim como a memória política 
que os fazem resistir ao branqueamento da sua cultura dentro da academia. Dentro desse pilar, fomos provocados a problematizar as concepções acadêmicas das ciências humanas e da saúde, que mantêm a cultura tribal à margem das discussões empíricas. Para isso, nos tornamos vetores, agentes de transformações sociais dentro da universidade, à medida que introduzimos nos nossos cursos as discussões sobre racismo, negritude, intolerância e diversidade religiosa, espiritualidade tribal, candomblé, modos de saúde produzidos pelos terreiros e suas atuações sociocomunitárias. Isso significou desmistificar questões sobre o povo tribal, que, no imaginário acadêmico, reduzem-se às discussões acerca da exploração escravocrata e da dominação europeia (CFP, 2017).

Comentando esse apagamento da cultura negra na educação, Nascimento (2008) concebe que tal prática faz referência a um processo desumanizador, tendo por consequência a manutenção de sistemas racistas que são devastadores para a construção da identidade do povo negro brasileiro, bem como a existência da tentativa de banir dos estudos as lutas dos negros contra os sistemas de opressão e a sua produção científica e tecnológica, mantendo apenas o olhar vitimizador. Isso corrobora para a representação da cultura negra africana ser "arcaica" e de ter tradição religiosa de "culto animista", demonizando qualquer referência tribal.

Por isso o aprender a conhecer no processo educativo envolve entender que a educação está conectada e inter-relacionada aos demais sistemas históricos, políticos, jurídicos, econômicos, socais e culturais, em que (co)existem componentes dialéticos entre esses sistemas que buscam, a partir de pontos de clivagem entre o político e o social, a afirmação de objetivos presentes no meio coletivo (LIBÂNEO; OLIVEIRA; TOSCHI, 2010).

Diante dessa problemática, o aprender a fazer amplia essas discussões. Recorremos à pesquisa como ferramenta estratégica para buscar estreitar o diálogo entre o terreiro com a academia a partir de produção científica (livros, artigos e resumos) disponível, que traz à tona o lugar do saber tribal na universidade com base na ótica da Psicologia. Os resultados desse fazer nos revelaram poucas discussões sobre essas temáticas, com tendência a polarizar o candomblé em uma perspectiva sociológica ou abarcar as experiências pelo olhar antropológico reducionista, além de mencionar a experiência de incorporação fundada em análises psicopatológicas (CFP, 2017).

Esses impasses das pesquisas nos mobilizaram a aprender a conviver com as limitações e diferenças epistemológicas, que significou trazer essas discussões para o ato coletivo, nas aulas, em seminários e congressos científicos em que, dentro da universidade, tentamos provocar movimentos que pudessem desmistificar qualquer posicionamento que enviesasse pela conversão religiosa ou a cristianização dos dogmas tribais. Tal atitude foi possível a partir do momento em que os monitores estenderam o saber construído na extensão para outros espaços. Desse modo, percebemos que o efeito da atividade acadêmica extrapolava os muros interinstitucionais, pois nos conduzia ao campo político e ético nas inter-relações com colegas, professores e comunidade, máxima em que a educação provoca a revolução, tornando-se bússola para disseminar as possibilidades de diálogo do saber candomblecista com a academia.

Da mesma forma, à medida que o projeto caminhava, cada monitor podia particularizar o saber tribal da experiência educativa. Isso significou que, mediante a vivência, não nos detivemos ao acúmulo de informações, bem como às exigências do frenesi acadêmico de produção científica. A cada encontro, nosso saber era construído no campo dinâmico das relações de pessoalidades entre todos os participantes do projeto, dando particularidade 
e unicidade do conteúdo aprendido ou ao momento vivido. Durante os encontros, nossas impressões de expressividade do saber particular emergiam e dialogicamente eram compartilhadas, conferindo o caráter implicativo de cada extensionista (FREIRE, 2014a). Os primeiros passos tomados para essa nova concepção proporcionada pela extensão são apontados por Serrano (2008) a partir da mudança do conceito de sala de aula, no qual o paradigma de transmissão do conhecimento entrou em crise. Agora, o conhecimento passou a ser discutido mediante a interconexão entre o empírico e o científico, por meio do estabelecimento de metodologias participativas e o contato dos universitários com o campo da sua práxis por meio dos estágios curriculares ou extracurriculares e as extensões acadêmicas.

Com esse estreitamento na relação academia-comunidade, os novos expoentes para a extensão universitária são apontados para a reorganização das propostas institucionais de educação. A Lei das Diretrizes Básicas da Educação Nacional (LDB) de 1996 - Lei no 9.394 - estabelece, em conformidade com a política educacional brasileira, que a extensão tem por objetivo envolver a participação popular no âmbito cultural, nas pesquisas científicas e na construção do conhecimento humano. As atribuições das instituições universitárias às exigências da extensão envolvem: a) uma sistematização na produção do conhecimento, de forma relevante, tanto no âmbito sociocomunitário, como nacional; b) a coparticipação e preparação do corpo docente para as atividades de extensão; c) estabelecimento de planos e programas de acordo com as possibilidades de atuação acadêmica; d) potencializar ações regionais de incentivo à cultura, justiça social, igualdade e respeito humano (BRASIL, 1996).

Essa dimensão humana abarca o aprender a ser proposto por Delors (1996), o que nos faz lembrar o que Morin (2005) discute a respeito das modificações de um saber, que é dado a partir de rupturas e transformações paradigmáticas que, muitas vezes, podem ser traumáticas. Todavia, possibilitam retificações objetivas e subjetivas na realidade de quem aprende, pois, o conhecimento não é marcado apenas pelo acúmulo e processamento de informações, ele é dinâmico, contínuo, relacional e antropológico.

Essas lutas provocaram rupturas e agrupamentos que conduziram a pensar um modelo educativo acadêmico pautado para a formação cidadã, no qual o educando amplia a sua preocupação para além do sentido formativo, pois engloba desarticular os sistemas de opressão de classes e políticos, assim como proporcionar a conscientização ecológica, histórica e cultural, construindo ações que terão impactos tanto no âmbito individual, como na coletividade (CANDAU, 2016).

\section{Considerações finais}

Diante das discussões de cunho teórico e reflexivo, a construção da extensão universitária partiu de uma perspectiva de tornar a universidade um espaço de debates políticos e sociais que busquem propiciar coletivamente o efeito de assegurar os direitos fundamentais a todas as pessoas. Além de encontros, acreditamos que a potencialidade dessa experiência tem reverberações na prática profissional, isto é, no trabalho de uma intervenção da realidade social.

Desterritorializar o modo que opera o tradicionalismo educacional, no qual as relações e os fluxos de poder remontam a um cenário de dominado e dominador, vem exigindo maior engajamento dos discentes quanto a encarar a sua futura profissão como um campo no qual esse profissional pode trabalhar de forma a manter o status quo da opressão ou contribuir para desenvolver estratégias emancipatórias.

Nesse sentido, a educação popular em saúde nas linhas freirianas foi essencial para 
a própria emancipação dos extensionistas do saber colonizador propagado pela universidade em formas de teorias e métodos, além de propiciar a compreensão crítica da realidade, bem como embasar uma práxis comprometida em assegurar a expressão dos modos de vida individuais e coletivos. Destacamos o empenho de todos os sujeitos envolvidos como forças que moveram as ações da extensão e foram efetivas para um debate coletivo e atuante do cotidiano.

As comunidades participantes da extensão mostraram perspectivas de fortalecimento de vínculos para além dos encontros programados pelo projeto. A partir dos encontros e encantos de cada povo de terreiro outras alianças foram se organizando e mobilizando novos sujeitos, e com isso novos propósitos foram surgindo, a saber: continuidade do projeto liderado pelos terreiros, participação social e ativismo nos fóruns populares de tolerância religiosa, conscientização do cuidado de saúde dialogado nas organizações religiosas, dentre outras demandas emergentes das comunidades.

Portanto, a educação popular segue uma via de mão dupla, em que a re-transformação ocorre em todos os elementos envolvidos, bem como a superação paradigmática de um saber pragmático. Dessa forma, chegase à perspectiva que, dentro do processo de ensino e aprendizagem, as relações éticas e políticas construídas entre os seres humanos podem possibilitar a construção do saber mútuo e coletivo sobre a subjetividade sem diluir sua forma de ser, mas combiná-las em busca de superar os desafios e maximizar as potencialidades dos atores envolvidos.

\section{Referências}

BONETTI, O. P.; CHAGAS, R. A. das; SIQUEIRA, T. C. A. A educação popular em saúde na gestão participativa do SUS: construindo uma política. In: Caderno de educação popular em saúde, v. II. Brasília: Ministério da Saúde: 2014. p. 16-24.

BRASIL. Ministério da Saúde. Secretaria de Gestão Estratégica e Participativa. Departamento de Apoio à Gestão Participativa. Política Nacional de Educação Popular em Saúde. Brasília: Ministério da Saúde, 2013.

. Lei de Diretrizes e Bases da Educação Nacional. Lei no 9.394, de 20 de dezembro de 1996. Estabelece as diretrizes e bases da educação nacional. Brasília, DF, 1996.

- Ministério da Saúde. Secretaria de Vigilância em Saúde. Departamento de Análise de Situação em Saúde. Saúde Brasil 2013: uma análise da situação de saúde e das doenças transmissíveis relacionadas à pobreza. Brasília: Ministério da Saúde, 2014.

. Portaria no 1.256, de 17 de junho de 2009. Institui o Comitê Nacional de Educação Popular em Saúde (CNEPS). Disponível em: <http://bvsms.saude.gov.br/bvs/saudelegis/gm/2009/ prt1256_17_06_2009.html>. Acesso em: 20 jul. 2018.

. Portaria no 992, de 13 de maio de 2009. Institui a Política Nacional de Saúde Integral

da População Negra. Disponível em: <http://bvsms.saude.gov.br/bvs/saudelegis/gm/2009/ prt0992_13_05_2009.html>. Acesso em: 23 jul. 2018. 
CANDAU, V. M. Educação em direitos humanos: desafios atuais. In: SILVEIRA, R. M. G. et al. (Org.). Educação em Direitos Humanos: fundamentos teóricos e metodológicos. João Pessoa: Editora Universitária da UFPB, 2007.

CONSELHO FEDERAL DE PSICOLOGIA - CFP. Relações raciais: referências técnicas para atuação de psicólogas/os. Brasília: CFP, 2017. Disponível em: < https://site.cfp.org.br/wp-content/ uploads/2017/09/relacoes_raciais_baixa.pdf> Acesso em: 10 ago. 2018.

DELORS, J. Educação: um tesouro a descobrir. Relatório para a Unesco da Comissão Internacional sobre Educação para o século XXI. Brasília: Faber-Castell, 1996.

FREIRE, P. Extensão ou comunicação? São Paulo: Paz e Terra, 2014a. 93 p. 2000. 134 p.

Pedagogia da indignação: cartas pedagógicas e outros escritos. São Paulo: Paz e Terra,

Educação como prática da liberdade. São Paulo: Paz e Terra, 2014b. 150 p.

GALLO, S. Modernidade/pós-modernidade: tensões e repercussões na produção de conhecimento em educação. Educação e Pesquisa, São Paulo, v. 32, n. 3, p. 551-565, 2006. Doi: http://dx.doi. org/10.1590/S1517-97022006000300009.

GHIRALDELLI JÚNIOR, P. A evolução das ideias pedagógicas no Brasil Republicano. Cadernos de Pesquisa, São Paulo, n. 60, p. 28-37, 2013.

LIBÂNEO, J. C.; OLIVEIRA, J. F.; TOSCHI, M. S. Organização escolar: políticas, estrutura e organização. São Paulo: Cortez, 2010. (Coleção Docência em Formação).

MELO, M. A. S; FILHO, A. dos S. G., QUEIROZ, Z. F. (Org.). Epistemologias em confronto no direito: reinvenções, ressignificações e representações a partir da interdisciplinaridade. Curitiba: CRV, 2017. 532 p.

MELO NETO, J. F. de. Extensão Popular. In: SOUSA, L. M. P. de et al. (Org.). Educação popular na universidade: reflexões e vivências da Articulação Nacional de Extensão Popular (ANEPOP), v. II. João Pessoa-PB: CCTA, 2017.

MOEHLECKE, S. Ação afirmativa: história e debates no Brasil. Cadernos de pesquisa, São Paulo, v. 117, n. 11, p. 197-217, nov. 2002.

MORIN, E. Os sete saberes necessários à educação do futuro. São Paulo: Unesco/Cortez, 2005. $130 \mathrm{p}$.

NASCIMENTO, E. L. Cultura em movimento: matrizes africanas e ativismo negro no Brasil. São Paulo: Selo Negro, 2008. 56 p. 
SERRANO, R. M. S. M. Conceitos de extensão universitária: um diálogo com Paulo Freire. 2008. Disponível em: <http://www.prac.ufpb.br/copac/extelar/atividades/discussao/artigos/conceitos_ de_extensao_universitaria.pdf>. Acesso em: 20 ago. 2018.

SILVA, A. V. Uma reflexão para a prática educativa em Paulo Freire. 2009. Disponível em: < http:// acervo.paulofreire.org:80/xmlui/handle/7891/4105>. Acesso em: 22 ago. 2018.

SOBRINHO, J. H. F. Cultura popular e as culturas afrodescendentes. In: HOLANDA, C. R. (Org.). Negros no Ceará: história, memória e etnicidade. Fortaleza: Museu do Ceará, Secretaria da Cultura do Estado do Ceará, 2009. (Coleção Outras Histórias, v. 61).

Submetido em 25 de setembro de 2018.

Aprovado em 5 de novembro de 2018. 